

\title{
Temperature Effect of Gas Bubble Evolution in UCN Fuel Kernels Irradiated by Swift Xe Ions
}

Chemical and Fuel Cycle Technologies Division 


\title{
About Argonne National Laboratory
}

Argonne is a U.S. Department of Energy laboratory managed by UChicago Argonne, LLC under contract DE-AC02-06CH11357. The Laboratory's main facility is outside Chicago, at 9700 South Cass Avenue, Lemont, Illinois 60439. For information about Argonne and its pioneering science and technology programs, see www.anl.gov.

\section{DOCUMENT AVAILABILITY}

Online Access: U.S. Department of Energy (DOE) reports produced after 1991 and a growing number of pre-1991 documents are available free at OSTI.GOV (http://www.osti.gov/), a service of the U.S. Dept. of Energy's Office of Scientific and Technical Information.

\author{
Reports not in digital format may be purchased by the public from the \\ National Technical Information Service (NTIS): \\ U.S. Department of Commerce \\ National Technical Information Service \\ 5301 Shawnee Rd \\ Alexandria, VA 22312 \\ www.ntis.gov \\ Phone: (800) 553-NTIS (6847) or (703) \\ 605-6000 Fax: (703) 605-6900 \\ Email: orders@ntis.gov
}

\section{Reports not in digital format are available to DOE and DOE contractors from the Office of Scientific and Technical Information (OSTI):}

U.S. Department of Energy

Office of Scientific and Technical Information

P.O. Box 62

Oak Ridge, TN 37831-0062

www.osti.gov

Phone: (865) 576-8401

Fax: (865) 576-5728

Email: reports@osti.gov

Disclaimer

\section{Disclaimer}

This report was prepared as an account of work sponsored by an agency of the United States Government. Neither the United States Government nor any agency thereof, nor UChicago Argonne, LLC, nor any of their employees or officers, makes any warranty, express or implied, or assumes any legal liability or responsibility for the accuracy, completeness, or usefulness of any information, apparatus, product, or process disclosed, or represents that its use would not infringe privately owned rights. Reference herein to any specific commercial product, process, or service by trade name, trademark, manufacturer, or otherwise, does not necessarily constitute or imply its endorsement, recommendation, or favoring by the United States Government or any agency thereof. The views and opinions of document authors expressed herein do not necessarily state or reflect those of the United States Government or any agency thereof, Argonne National Laboratory, or UChicago Argonne, LLC. 
ANL/CFCT-20/27

\section{Temperature Effect of Gas Bubble Evolution in UCN Fuel Kernels Irradiated by Swift Xe lons}

prepared by

Sumit Bhattacharya ${ }^{1}$, Yinbin Miao ${ }^{1}$, Kun Mo${ }^{1}$, Laura Jamison ${ }^{1}$, Rachel Seibert ${ }^{2}$, Andrew Nelson ${ }^{2}$, Heather Connaway ${ }^{1}$, and Abdellatif Yacout ${ }^{1}$

1) Argonne National Laboratory

2) Oak Ridge National Laboratory

June 2021 
(This page left intentionally blank) 


\section{Abstract}

UC1-xNx fuel kernels provided by Oak Ridge National Laboratory (ORNL) were irradiated by 84 $\mathrm{MeV} \mathrm{Xe}$ ions at two different temperatures $\left(450^{\circ} \mathrm{C} \& 750^{\circ} \mathrm{C}\right)$ at the Argonne Tandem Linac Accelerator System (ATLAS) at Argonne National Laboratory, followed by post-irradiation examination. The primary goal of this study was to understand gas bubble formation (due to accumulation of Xe gas) and corresponding size evolution dependent upon net Xe deposition at the two different temperatures. From the post-irradiation examinations of the samples, it can be concluded at $750^{\circ} \mathrm{C}$, with same amount of dose received, the Xe gas bubbles seems to coarsen much more easily compared to $450^{\circ} \mathrm{C}$. The results generated for fission gas bubble evolution observed in this study can be used to support fuel performance models for UC1-xNx fuel kernels. 


\section{Table of Contents}

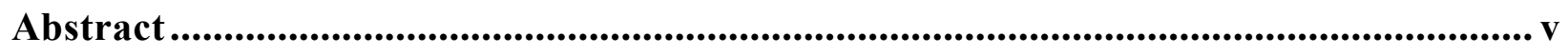

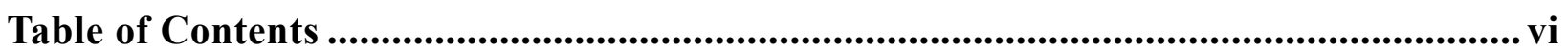

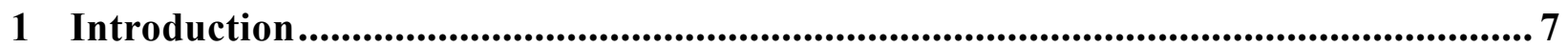

2 Experimental Procedure ............................................................................................... 7

2.1 Samples and Swift Ion Irradiation .......................................................................... 7

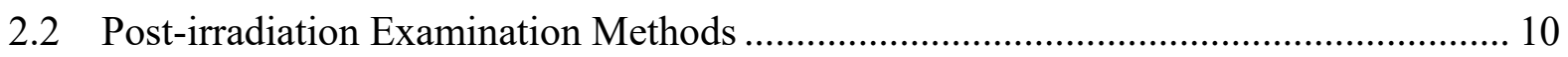

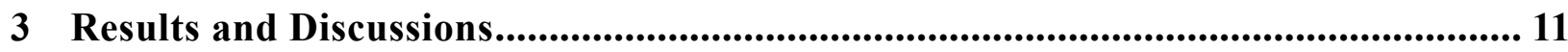

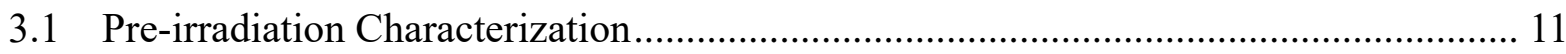

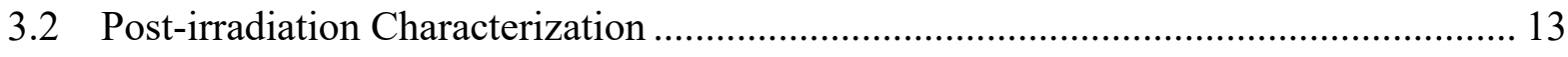

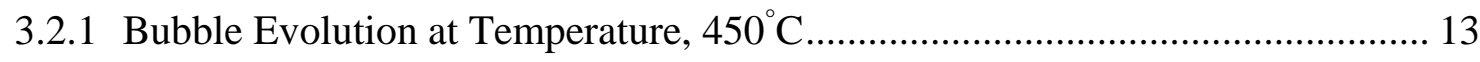

3.2.1.1 Bubble Size Distribution and Density in Region 1 1.............................. 15

3.2.1.2 Bubble Size Distribution and Density in Region 2 2............................... 16

3.2.1.3 Bubble Size Distribution and Density in Region 3 ............................. 17

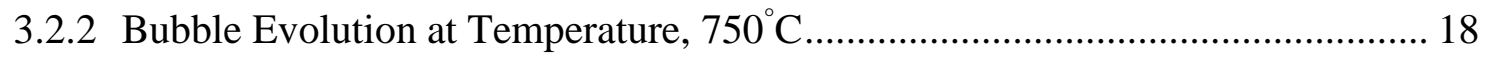

3.2.2.1 Bubble Size Distribution and Density in Region 1 .............................. 20

3.2.2.2 Bubble Size Distribution and Density in Region 2............................. 20

3.2.2.3 Bubble Size Distribution and Density in Region 3 ………………....... 21

3.3 Comparison between Bubble Size Distribution......................................................... 22

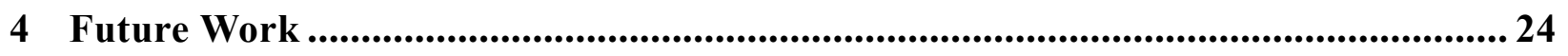

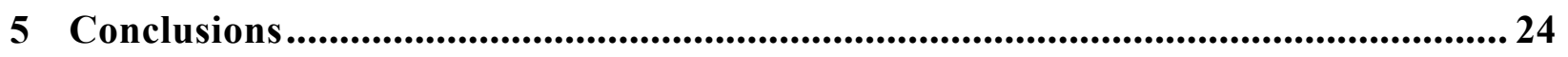

Acknowledgement ......................................................................................................................... 24

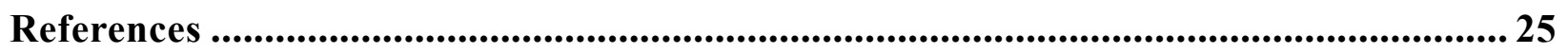




\section{Introduction}

The post-irradiation examination (PIE) results of as-received UC1-xNx fuel kernels provided by Oak Ridge National Laboratory (ORNL) and irradiated by $84 \mathrm{MeV}$ Xe ions at two different temperatures $\left(450^{\circ} \mathrm{C} \& 750^{\circ} \mathrm{C}\right)$ are reported here.

The as-fabricated UC1-xNx fuel kernels used for performing heavy ion irradiation have an FCC crystal structure with macro grains. The main goal of this study was to understand gas bubble formation (due to accumulation of Xe gas) and corresponding size evolution dependent upon net Xe deposition at two different temperatures. After irradiation by $84 \mathrm{MeV}$ Xe ions at $450^{\circ} \mathrm{C} \&$ $750^{\circ} \mathrm{C}$ to reach up to $8.94 \mathrm{E}+17$ ions $/ \mathrm{cm}^{2}$ fluence, the quantitative bubble morphology data has been collected and presented in detail. The ion irradiation testing technique can provide initial data that may be beneficial to fuel candidate down-selection, or to support other technical decisions. This data can also provide valuable references for the development and validation of fuel performance models.

\section{Experimental Procedure}

\subsection{Samples and Swift Ion Irradiation}

Swift ions are implanted into samples in one direction, and form radiation damage and a foreign atom deposition profile as a function of depth. Hence, the radiation dose can be quantified given the depth from surface. In order to produce irradiated specimens with well-defined radiation dose, $\mathrm{UC1}-\mathrm{xNx}$ fuel kernels in powder format were directly utilized. In this study, UC1-xNx fuel kernels used has a diameter of $\sim 810$ microns. The swift ion irradiation was conducted at the Argonne Tandem Linac Accelerator System (ATLAS) at Argonne National Laboratory [1, 2]. Four UC1xNx fuel kernels were mounted on each of three separate sample stages made of oxygen-free high conductive (OFHC) copper using PELCO high conductivity silver paste. A Heatwave Lab. TB175 cartridge heater was also fastened on each sample stage to provide a heat source when elevated irradiation temperature is needed. Details of the ion irradiation sample stage can be found in Figure 
1 and Figure 2. A $84 \mathrm{MeV}$ Xe ion beam was used to irradiate these samples at two different temperatures: $450^{\circ} \mathrm{C}, 750^{\circ} \mathrm{C}$. The ion beam has an approximate $2 \mathrm{D}$ Gaussian profile with a $\sigma \mathrm{x}$ parameter of $1.47 \mathrm{~mm}$, a $\sigma y$ parameter of $2.19 \mathrm{~mm}$, and a current of 300 particle nano-ampere (pnA). More detailed irradiation condition information can be found in Table 1.

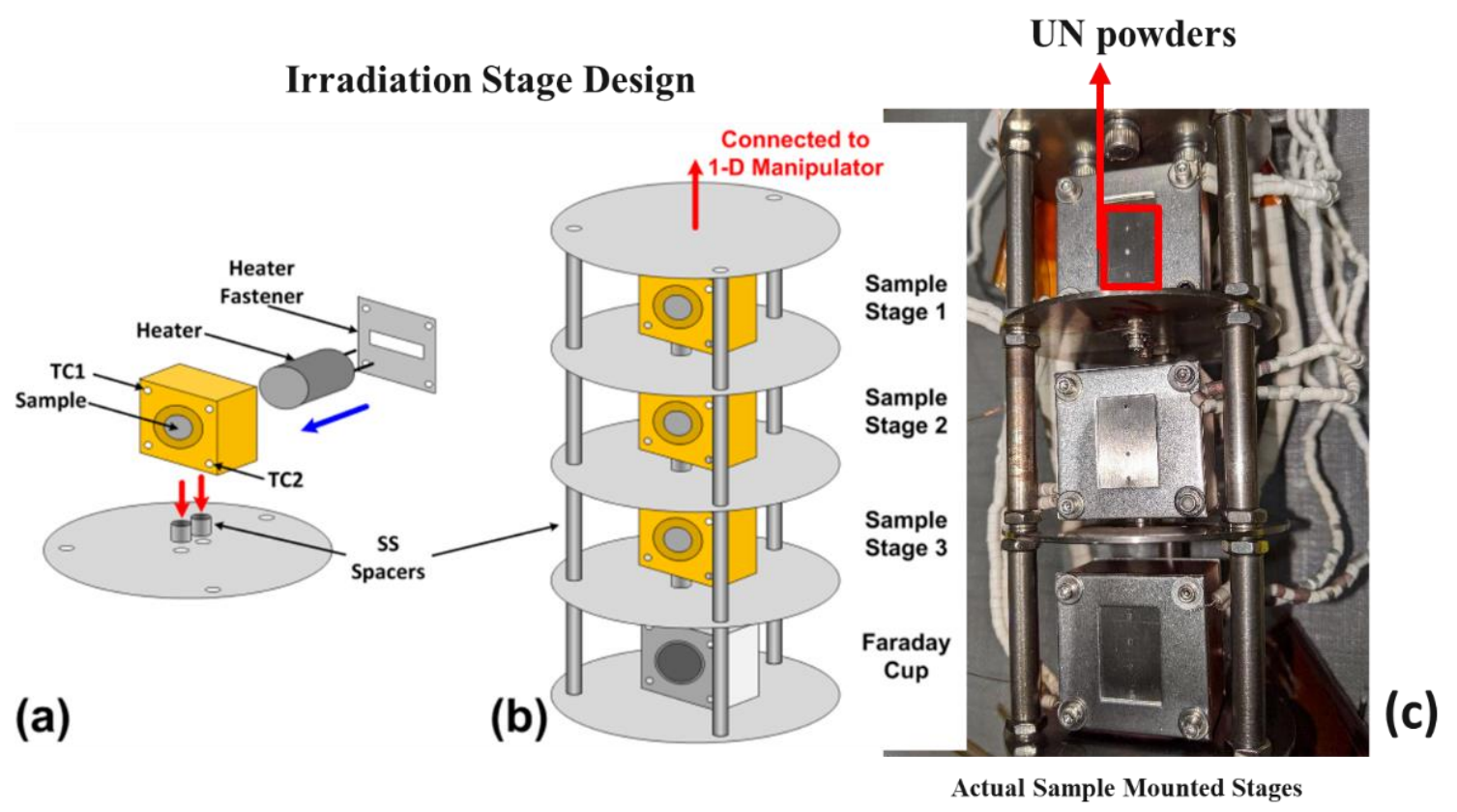

Figure 1: Setup of the swift ion irradiation experiment: (a) a schematic drawing of the ion irradiation stage used in this study; (b) a photographic image of the ion irradiation stage. 


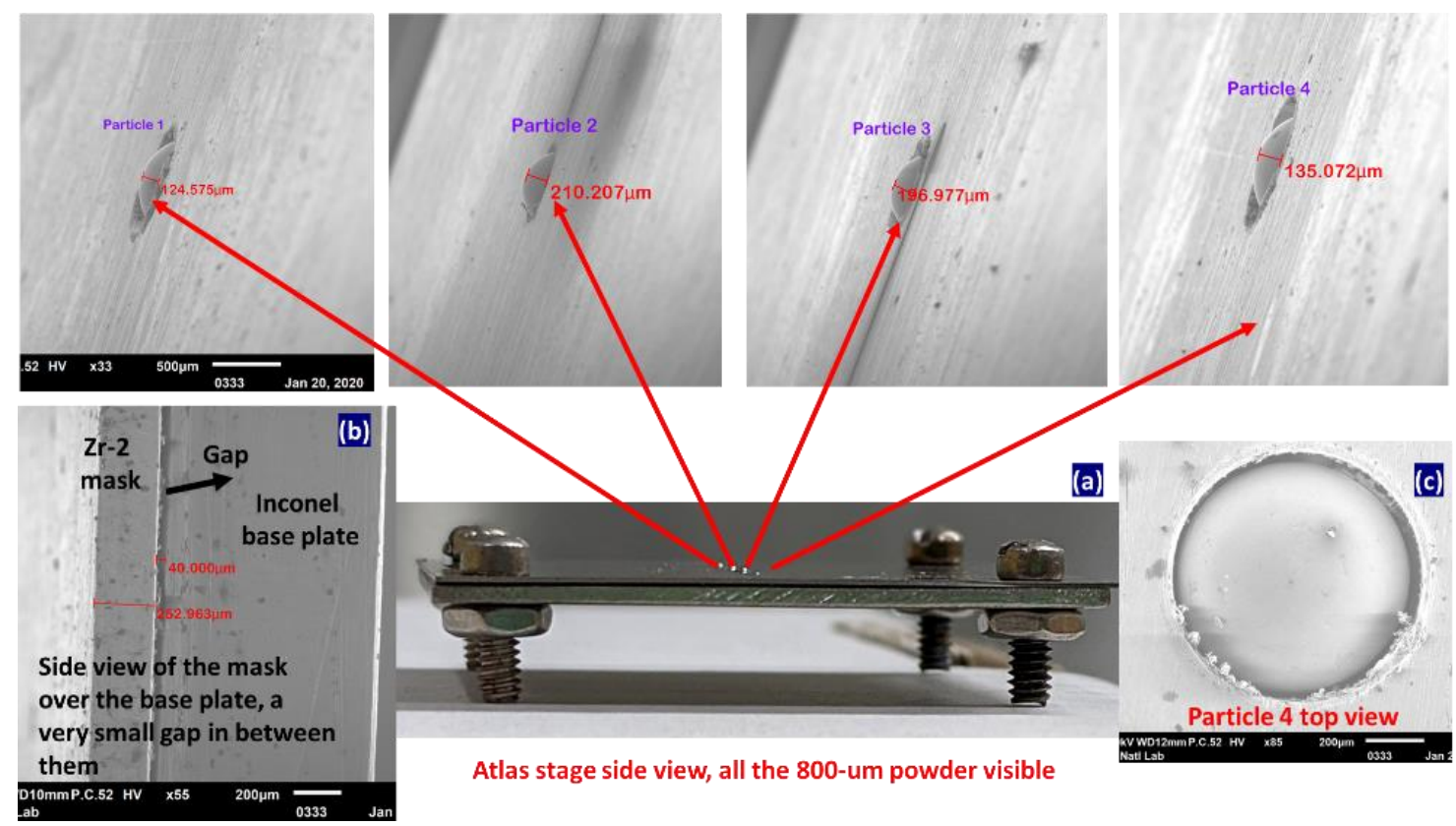

Figure 2: A closeup photographic image of the ion irradiation stage, showing the exposed regions of the powder which will be irradiated with SWIFT Xe ions. A Zircaloy mask has been used to provide support to the powder and also prevent irradiation of the silver paste which may lead to uncontrolled contamination.

Table 1: Radiation conditions of the $\mathrm{UC}_{1-\mathrm{x}} \mathrm{N}_{\mathrm{x}}$ specimens investigated in this study.

\begin{tabular}{|l|c|c|l|c|c|}
\hline Materials & $\begin{array}{c}\text { Temp } \\
\left({ }^{\mathbf{0}} \mathbf{C}\right)\end{array}$ & $\begin{array}{c}\text { Current } \\
(\mathbf{p n A})\end{array}$ & $\begin{array}{c}\text { Max Dose } \\
\left(\mathbf{i o n s} / \mathbf{c m}^{2}\right)\end{array}$ & $\begin{array}{c}\text { Eq. BU } \\
\text { (DPA, } \\
\text { peak/avg) }\end{array}$ & $\begin{array}{c}\text { Time } \\
\text { (Hour) }\end{array}$ \\
\hline \multirow{2}{*}{$\mathbf{U C}_{\mathbf{1 - \mathbf { x }} \mathbf{N}_{\mathbf{x}}}$} & $\sim 750$ & 300 & $8.94 \mathrm{E}+17$ & $5.0 \% / 1.87 \%$ & $\sim 36$ \\
\cline { 2 - 6 } & $\sim 450$ & 200 & $8.94 \mathrm{E}+17$ & $5.0 \% / 1.87 \%$ & $\sim 54$ \\
\hline
\end{tabular}


The radiation dose and deposited $\mathrm{Xe}$ profiles of the $84 \mathrm{MeV} \mathrm{Xe}$ ions in the $\mathrm{UC}_{1-\mathrm{x}} \mathrm{N}_{\mathrm{x}}$ fuel kernels were calculated using SRIM [3] according to Stoller et al.'s guideline [4] with the following displacement energies $\left(\mathrm{E}^{\mathrm{U}}=47 \mathrm{eV}[5], \mathrm{E}^{\mathrm{N}}=28.0 \mathrm{eV}[6]\right.$, and $\left.\mathrm{E}^{\mathrm{C}}=28.0 \mathrm{eV}[7]\right)$. The results are illustrated in Figure 3. It is clear that the peak radiation damage occurs $\sim 6.8$ micrometer from the surface, whereas the overwhelming majority of the Xe atoms were deposited at $\sim 7.5$ micrometer. During the ion irradiation, the temperature fluctuation was limited within $\pm 10{ }^{\circ} \mathrm{C}$, except for some occasional beam interruption events.



Figure 3: Xe deposition and radiation dose profile calculated by SRIM

\subsection{Post-irradiation Examination Methods}

The gas bubble formation within these irradiated $\mathrm{UC}_{1-\mathrm{x}} \mathrm{N}_{\mathrm{x}}$ fuel kernels were first examined using scanning electron microscopy. In order to expose the cross-sections of the specimens, focused ion beam (FIB) was used to mill these irradiated specimens. An FEI Strata 400 SEM-FIB Dual Beam system, which has a Ga-ion FIB source and a field emission gun (FEG) electron source, was adopted for the SEM investigation. A systematic study of the gas bubble distribution along the damage plane correlated with both Xenon deposition at two different temperature was performed. Two thin foil specimens were lifted out from the irradiated $\mathrm{UC}_{1-\mathrm{x}} \mathrm{N}_{\mathrm{x}}$ fuel kernels using an FEI 
Quanta 3D FEG scanning electron microscope/focused ion beam (SEM/FIB) Dual Beam system. Both samples were prepared with materials dug from the center of the ion beam footprint which received maximum dosage. These two lamellae were mounted onto a copper Omniprobe TEM grid using the Pt deposition available in the Dual Beam system. Two rectangular areas of approximately $10 \mu \mathrm{m}$ (width) $\times 10 \mu \mathrm{m}($ depth) on the HD foil were further thinned to electron transparency (approximately $100 \mathrm{~nm}$ ) by the FIB. These three thin areas were cleaned by $5 \mathrm{keV}$ and $2 \mathrm{keV} \mathrm{Ga}$ ions to minimize the artificial radiation damage induced by FIB. TEM characterizations were conducted on a Hitachi 9000 in IVEM facility at ANL. A series of imaging techniques, including TEM bright-field (BF) diffraction contrast imaging was utilized to investigate the microstructure modifications and gas bubble evolution induced by Xe ions.

\section{Results and Discussions}

\subsection{Pre-irradiation Characterization}

This step was performed to document the kernel microstructure before it was irradiated, to ensure that any changes after irradiation could be identified. Figure $4(a, b)$ shows the typical morphology and surface condition of the as-received fuel kernels from ORNL. The kernel presents a rough texture, with observable surface oxidation (Fig. 1(b)) most likely due to exposure in the ambient atmosphere during transport and analysis. Detailed surface compositions can be found in Table 2 . From FIB characterization data, the kernels are relatively dense, with large grain size $(\sim 20-25$ microns) as seen in figure $5(a, b)$. 
(a)

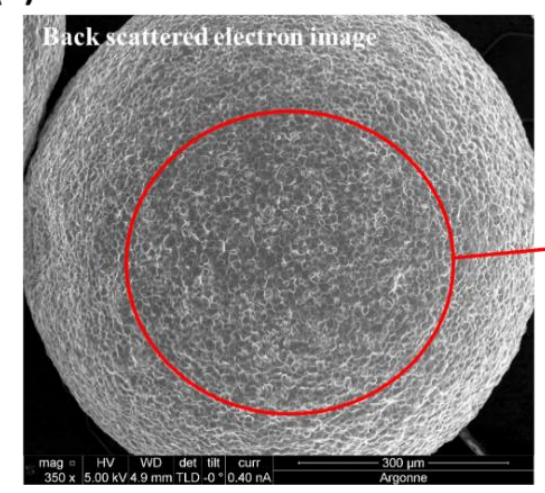

(b)

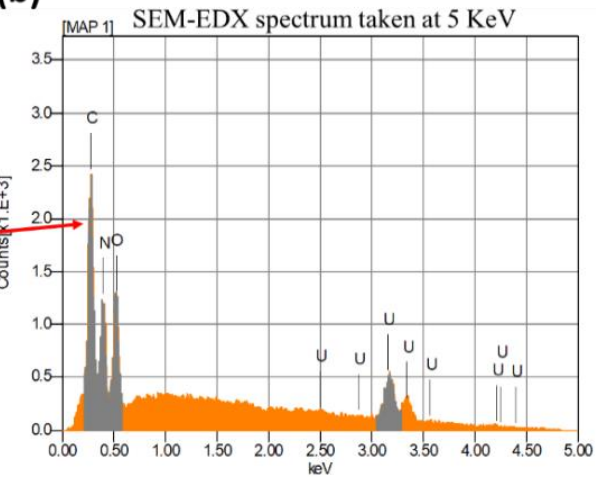

Figure 4: (a) $\mathrm{UC}_{1-\mathrm{x}} \mathrm{N}_{\mathrm{x}}$ fuel kernels as received from ORNL; (b) EDS spectrum performed over the kernel surface (marked by red circle).

Table 2: $\mathbf{U C}_{1-\mathrm{x}} \mathrm{N}_{\mathbf{x}}$ fuel kernels surface composition

\begin{tabular}{|c|r|r|}
\hline Elements & mass\% & Atom\% \\
\hline $\mathrm{C}$ & 1.65 & 18.88 \\
\hline $\mathrm{N}$ & 1.59 & 15.66 \\
\hline $\mathrm{O}$ & 1.17 & 10.10 \\
\hline $\mathrm{U}$ & 95.59 & 55.36 \\
\hline
\end{tabular}

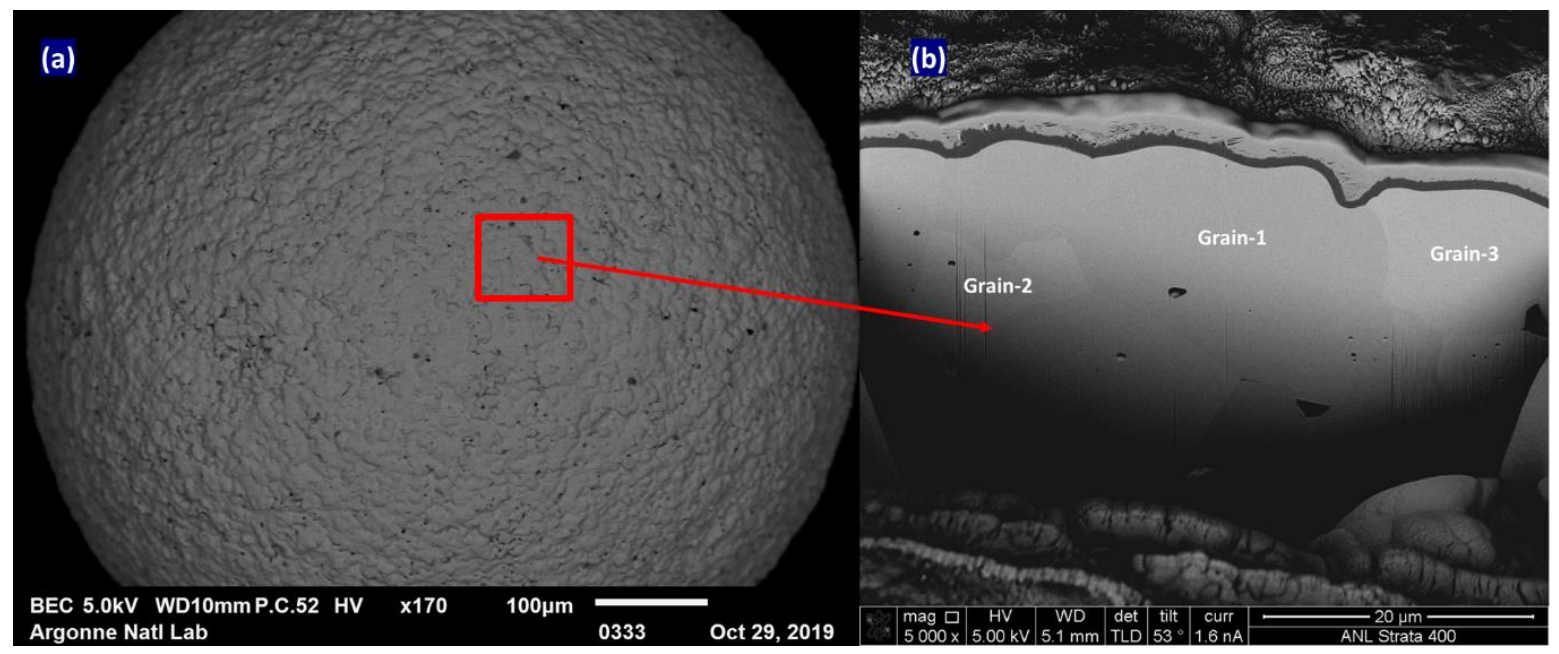

Figure 5: BSE image of (a) as received UCN kernel from ORNL and (b) After FIB cross section to study the grain size and distribution. 


\subsection{Post-irradiation Characterization}

\subsubsection{Bubble Evolution at Temperature, $450^{\circ} \mathrm{C}$}

The overall microstructure for the $\mathrm{UC} 1-\mathrm{xNx}$ specimen is shown in figure 6. During analysis, diffraction rings were identified as uranium oxide. Such oxidations may have been a result of the brief exposure of the $\sim 50 \mathrm{~nm}$ thick air sensitive UN system specimen to ambient conditions or as result of oxidation during Xe ion irradiation process. Such surface oxidation has been found to be common in uranium systems under ion irradiation. With help of SADP the orientation of the twograin marked as Grain 1 and 2 (dark blue), have been identified. Grain 1 has a [1 11] orientation while Grain 2 has a [112 $]$ orientation. From SADP analysis the crystal structure of the system is also identified as face centered cubic (FCC).

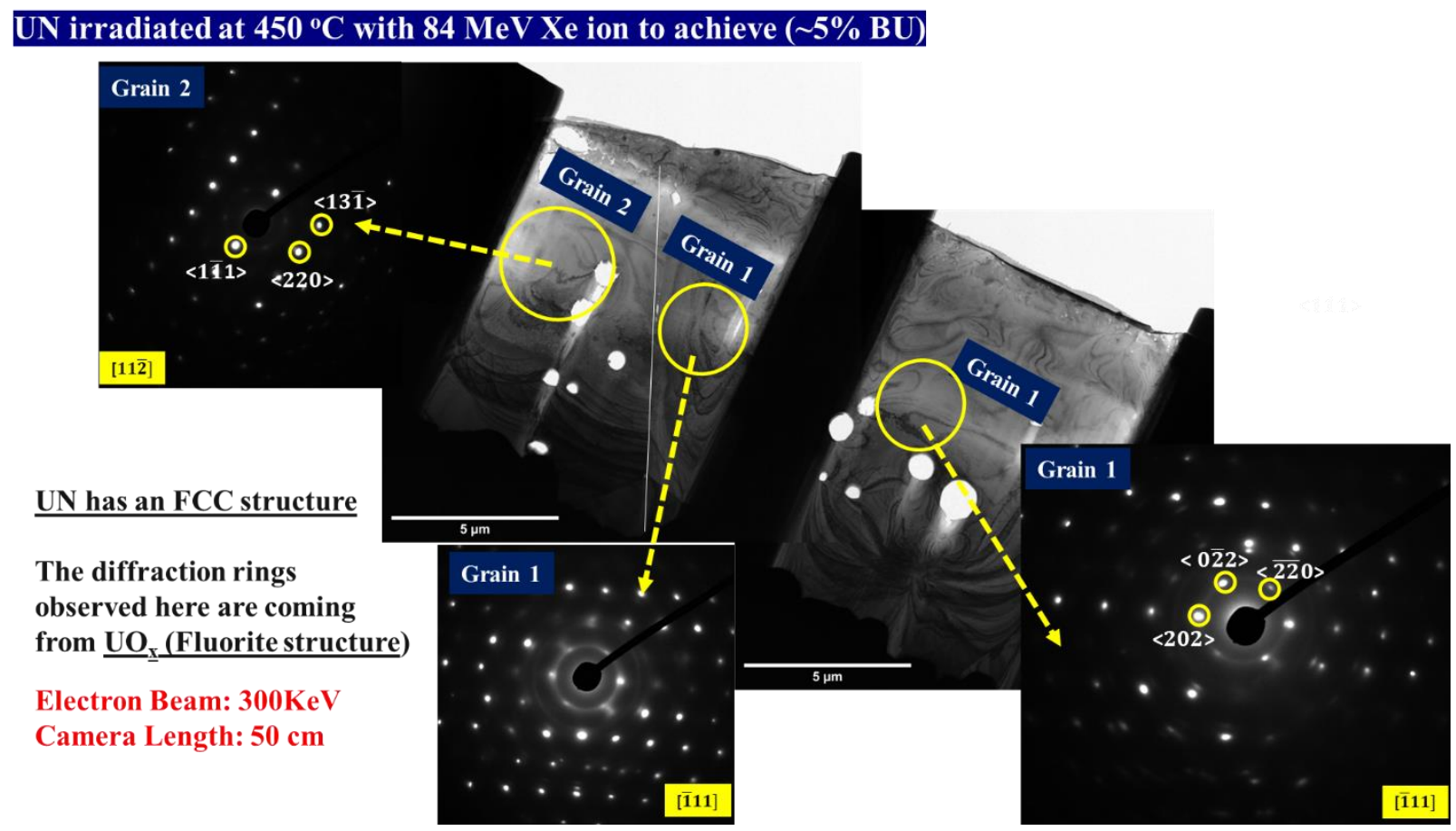

Figure 6: Detailed SADPs of the two visible grains in the bright field image of the TEM foil identified as Grain 1 and Grain 2. From detailed analysis it is found that the orientation of these two grains are $\left[\mathbf{1}^{11}\right]$ and $[112 \overline{]}$ respectively belonging to an FCC crystal structure. 


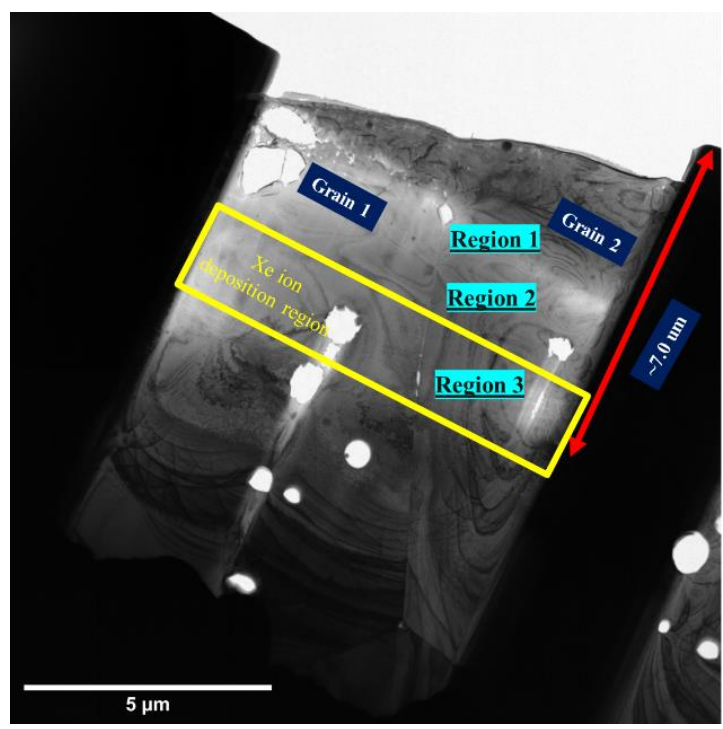

Figure 7: Bright field image of the left portion of the TEM foil (selected for characterizing the bubbles). The red arrow indicates the region of the foil where the heavy ion Xe has interacted and deposited ( 7.5 micrometer from top). Region 1, 2, \& 3 marked in blue are selected to study the bubble size distribution vs. specimen depth.

For gas bubble size distribution analysis for this temperature, the most uniformly-bright region of the sample is chosen, the left portion of the thinned foil shown in Figure 7. Following the SRIM calculation for Xe concentration with depth and corroborating the estimated depth for maximum Xe deposition from the bright field image, it can be said that at $\sim 7.5$ micrometer from top is the region (marked by red arrow). In order to calculate the bubble density and size variation with depth, characterization was performed per region 1, 2, \& 3 marked in blue (Figure 7). 


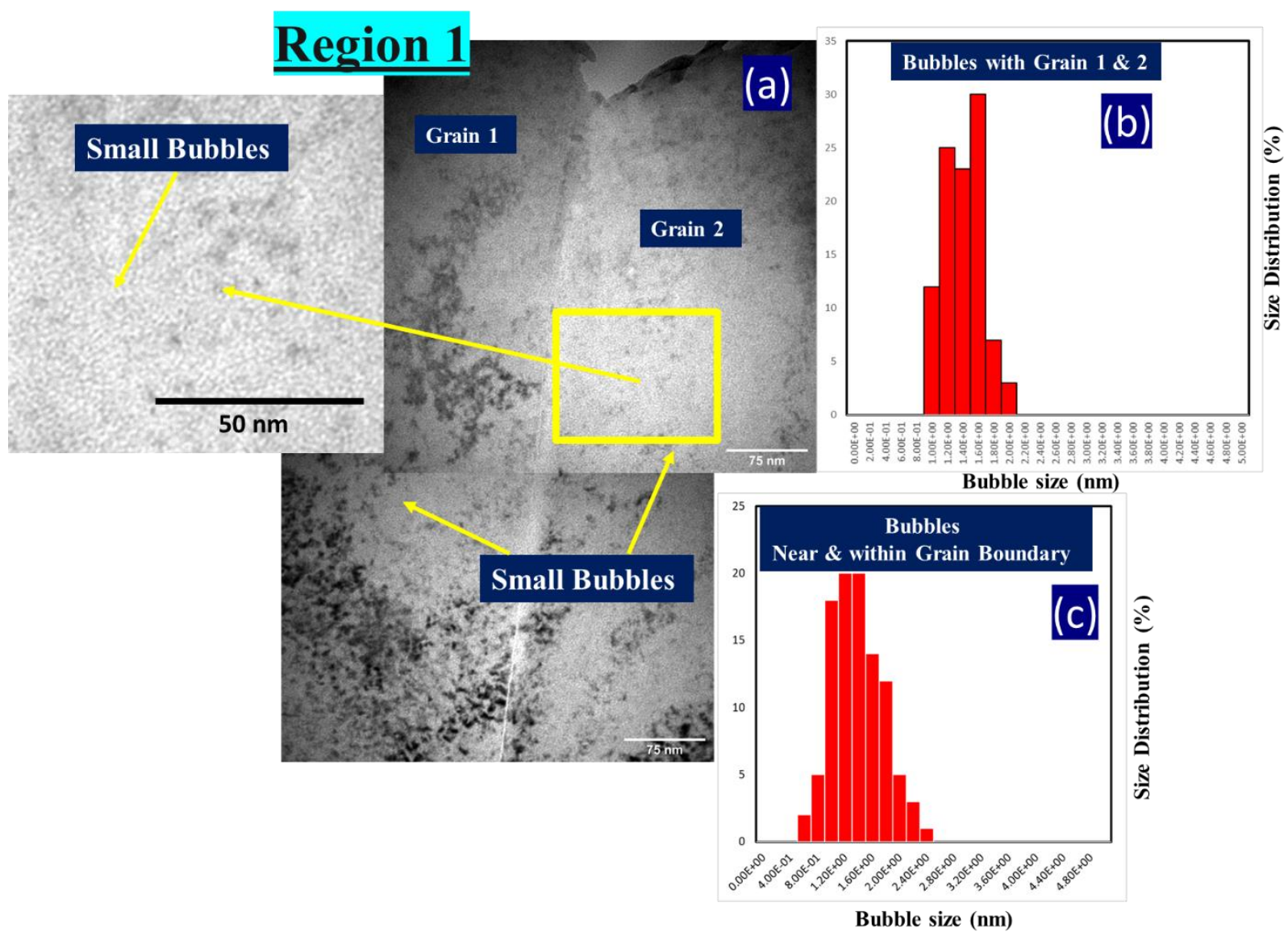

Figure 8: (a) Bright field image of the Region 1 of the TEM foil where the two grains (1 and 2) are meeting. In region 1 only nano bubbles have formed and its corresponding bubble size distribution is presented in (b) monomodal size distribution of Xe bubbles in the both Grain 1 and 2, with average size of $\sim 1.4 \mathrm{~nm}$ (c) monomodal size distribution of Xe bubbles present in the grain boundary region, with average size of $\sim 1.6 \mathrm{~nm}$.

\subsubsection{Bubble Size Distribution and Density in Region 1}

The Xe bubbles formed in Region 1 are all similar in dimension and very uniformly distributed. This is true for both grains 1 and 2. All the bubbles present within the grains are generally of the dimension of $\sim 1.0$ to $\sim 1.5 \mathrm{~nm}$, whereas for the nano bubbles formed near or within the grain boundary are slightly larger but not significant, details can be found in Figure 8 (a). The exact bubble size distribution (\%) details for both within the grain and present in the grain boundary can be found in figure $8(\mathrm{~b}, \mathrm{c})$. The estimated bubble density for this region is $\sim 1.2 \mathrm{E}+18 /$ cc for both bubbles present within grains and at grain boundaries. 


\section{$\underline{\text { Region } 2}$}

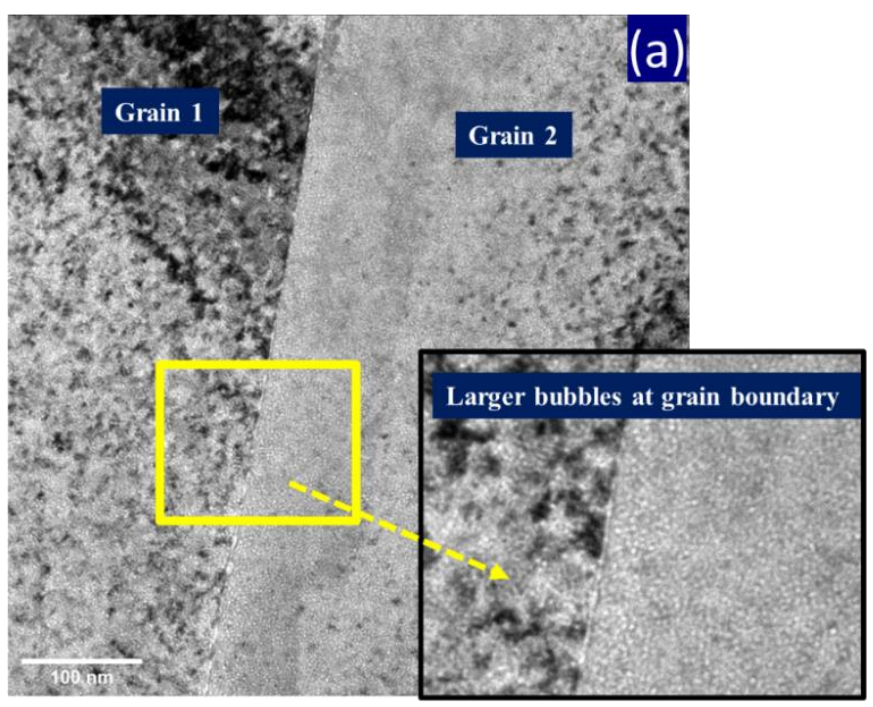

Bubbles with Grain $1 \& 2$

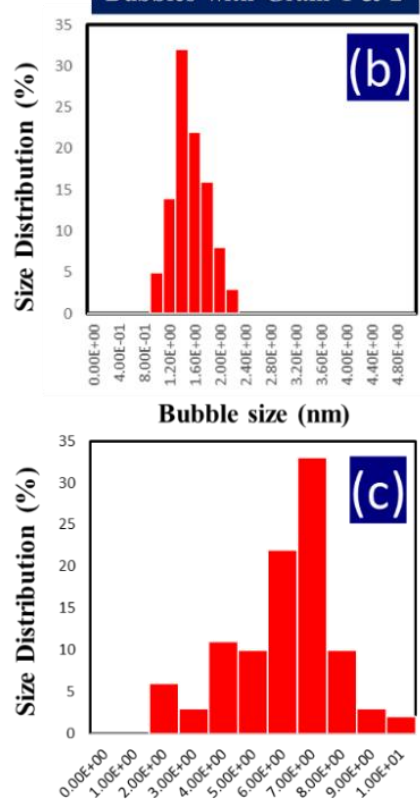

Bubbles

Near \& within Grain Boundary

Figure 9: (a) Bright field image of the Region 2 of the TEM foil where the two grains (1 and 2) are meeting. In region 2 , only nano bubbles have formed, but the nano bubbles present in the grain boundary region, which are $\sim 2 x$ to $3 x$ bigger than the bubbles formed within the grains (shown in the enlarged image). The corresponding bubble size distribution is presented in (b) monomodal size distribution of Xe bubbles in the both Grain 1 and 2, with average size of $\sim 1.5 \mathrm{~nm}$ (c) monomodal size distribution of Xe bubbles present in the grain boundary region, with average size of $\sim 6 \mathrm{~nm}$.

\subsubsection{Bubble Size Distribution and Density in Region 2}

The Xe bubbles formed in Region 2, especially in both grains ( 1 \& 2), are also similar in dimension like in Region 1, and very uniformly distributed. All of the bubbles present within the grains are generally of the dimension of $\sim 1.2$ to $\sim 1.5 \mathrm{~nm}$, whereas for the nano bubbles formed near or within the grain boundary are larger by $\sim 2 \mathrm{x}$ to $3 \mathrm{x}$ than the bubbles formed within the grains (details in Figure 9 (a)). In the box displaying an expanded region of the grain boundary region, the larger bubbles can be seen. The exact bubble size distribution (\%) details for both within grain and present in grain boundary can be found in figure 9 (b, c). The estimated bubble density for this region is $\sim 8.2 \mathrm{e}+17 / \mathrm{cc}$ and $3.92 \mathrm{e}+17 / \mathrm{cc}$ for the bubbles present at the grain boundary. 

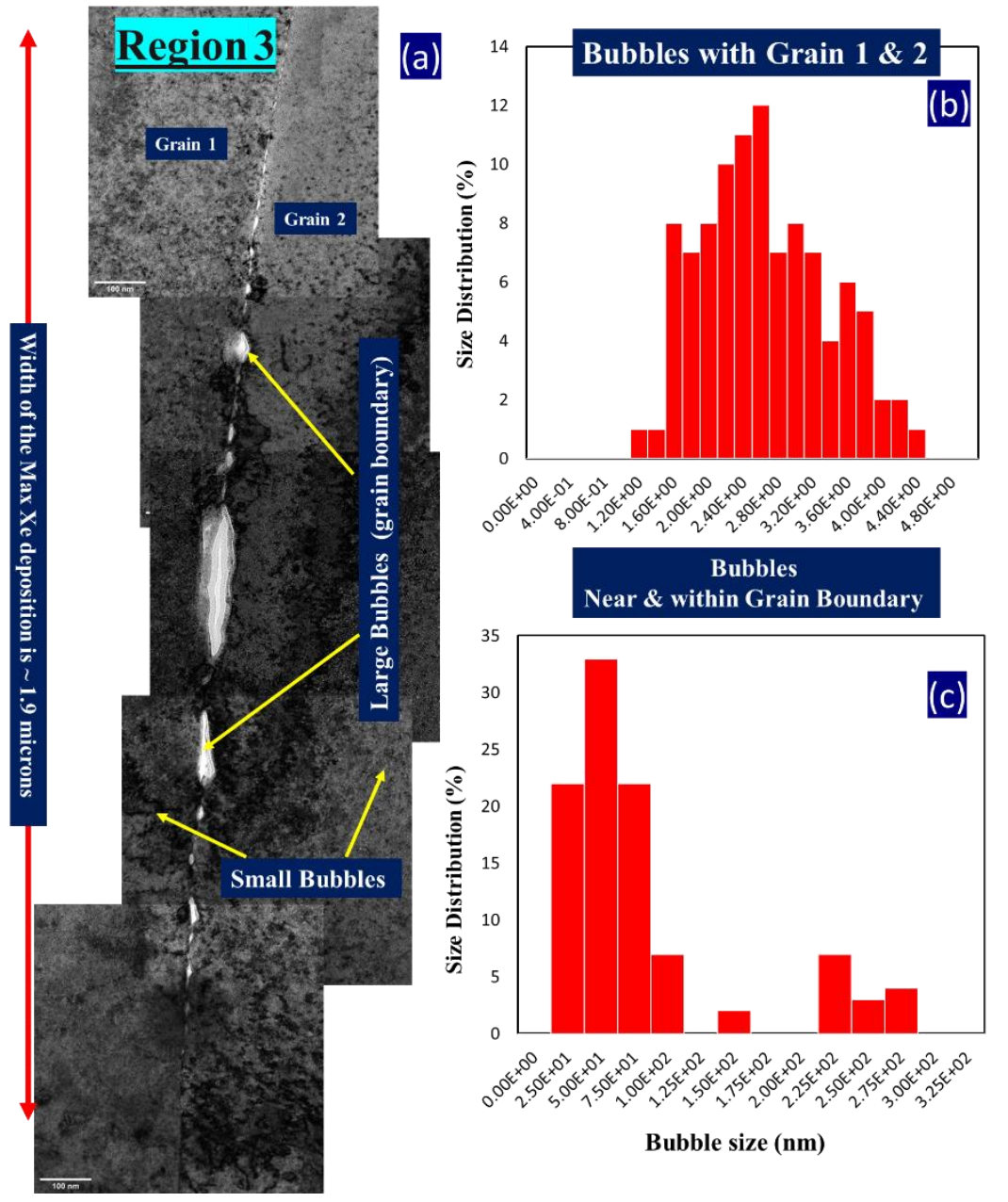

Figure 10: (a) Bright field image of the Region 3 of the TEM foil where the two grains (1 and 2) are meeting. In region 3, not only nano bubbles are identified, but the large submicron bubbles present in the grain boundary region, which are $\sim 2$ orders of magnitude bigger than the bubbles formed within the grains (shown in the enlarged image). The corresponding bubble size distribution is presented in (b) monomodal size distribution of Xe bubbles in the both Grain 1 and 2 , with average size of $\sim 3 \mathrm{~nm}$ (c) bimodal bubble size distribution of Xe bubbles present in the grain boundary region, ranging from $\sim 30 \mathrm{~nm}$ to $280 \mathrm{~nm}$ in size.

\subsubsection{Bubble Size Distribution and Density in Region 3}

Region 3 represents the region of Xe bubble formation formed near or on the Xe deposition peak. In Region 3, not only are nano bubbles identified, but large sub-micron bubbles are also present in the grain boundary region, which are $\sim 2$ orders of magnitude bigger than the bubbles formed 
within the grains (shown in the enlarged image). The exact bubble size distribution (\%) details for both within grain and present in grain boundary can be found in figure $10(\mathrm{~b}, \mathrm{c})$. The estimated bubble density for this region is $\sim 4.8 \mathrm{e}+16 / \mathrm{cc}$ and $2 \mathrm{e}+15 / \mathrm{cc}$ for the bubbles present at the grain boundary.

\subsubsection{Bubble Evolution at Temperature, $750^{\circ} \mathrm{C}$}

The overall microstructure for the $\mathrm{UC}_{1-\mathrm{x}} \mathrm{N}_{\mathrm{x}}$ specimen irradiated with $84 \mathrm{MeV} \mathrm{Xe}$ ions at $750^{\circ} \mathrm{C}$ is shown in Figure 11. The TEM foil used for this analysis is $\sim 65 \mathrm{~nm}$ thick. With help of SADP analysis it is found that the region is actually one large macro grain with orientation [1 11] respectively belonging to an FCC crystal structure.

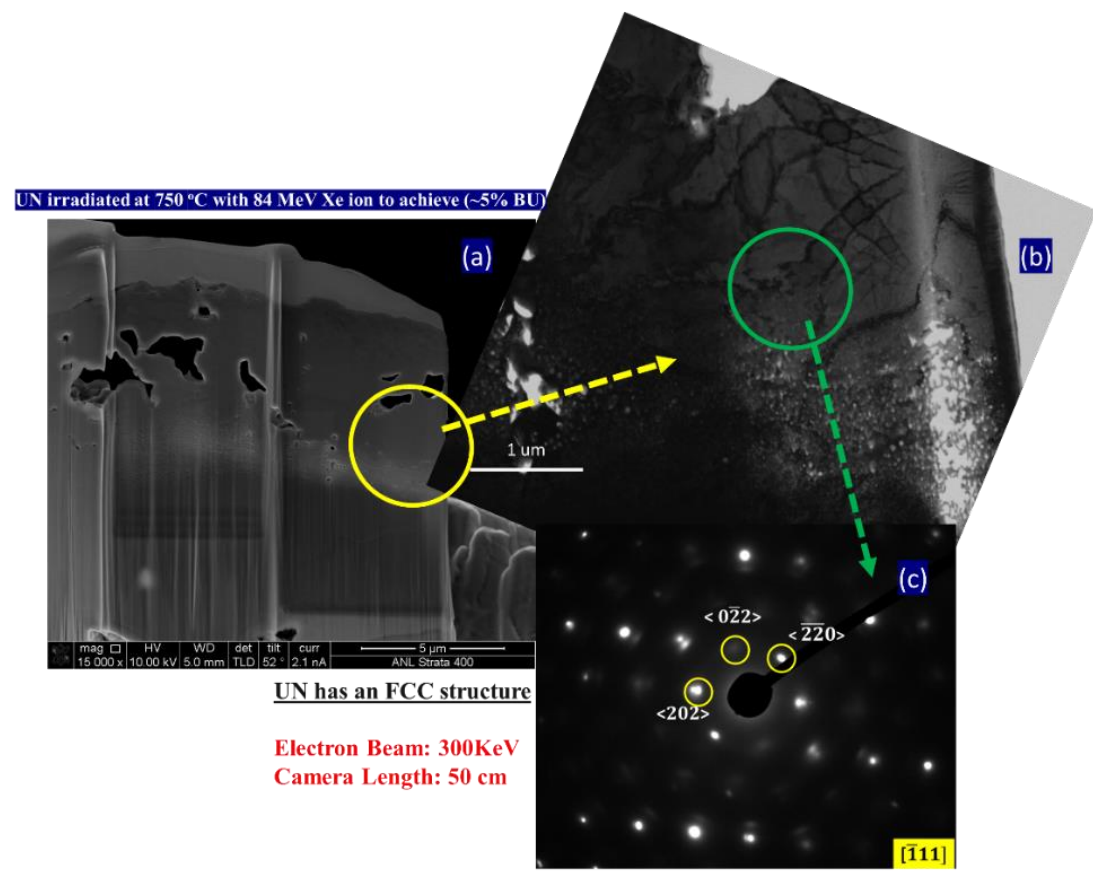

Figure 11: Detailed SADPs of the region identified in the bright field image (green circle). From detailed analysis it is found that the region is actually one large macro grain with orientation [1-11] respectively belonging to an FCC crystal structure.

For gas bubble size distribution analysis for the $\mathrm{UC}_{1-\mathrm{x}} \mathrm{N}_{\mathrm{x}}$ fuel kernels irradiated at $750^{\circ} \mathrm{C}$ temperature, a part of the foil was selected where it is uniformly thick, thus delivering uniform illumination over the selected region of the sample, shown in Figure 11. Following the SRIM 
calculation for Xe concentration with depth and corroborating the estimated depth for maximum Xe deposition from the bright field image, it can be said that at $\sim 7.5$ micrometer from top is the region (marked by yellow box). In order to calculate the bubble density and size variation with depth, the characterization was performed per Regions 1, 2, \& 3 marked in blue (Figure 12).

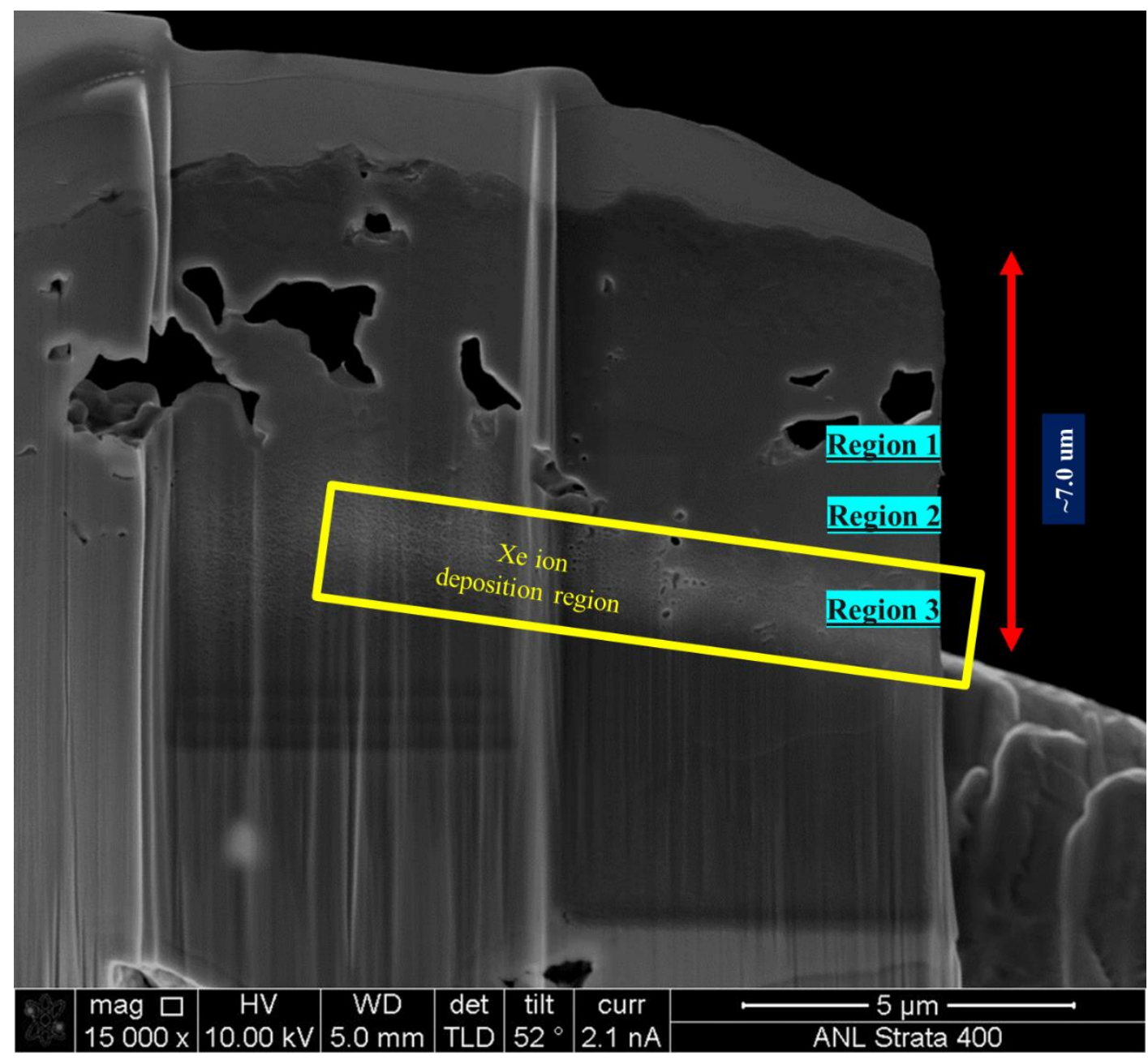

Figure 12: BSE image of the left portion of the TEM foil (selected for characterizing the bubbles). The red arrow indicates the region of the foil where the heavy ion Xe has interacted and deposited ( 7.5 micrometer from top). Region 1, 2, \& 3 marked in blue are selected to study the bubble size distribution with depth. 


\subsubsection{Bubble Size Distribution and Density in Region 1}

The Xe bubbles formed in Region 1 are all similar in dimension and very uniformly distributed in the observed region. The dimensions of the bubbles present here vary from $\sim 1.0$ to $\sim 2.3 \mathrm{~nm}$. More details can be found in Figure 13 (a). The exact bubble size distribution (\%) details can be found in figure 13 (b). The estimated bubble density for this region is $\sim 9.6 \mathrm{e}+17 / \mathrm{cc}$.

\section{$\underline{\text { Region } 1}$}



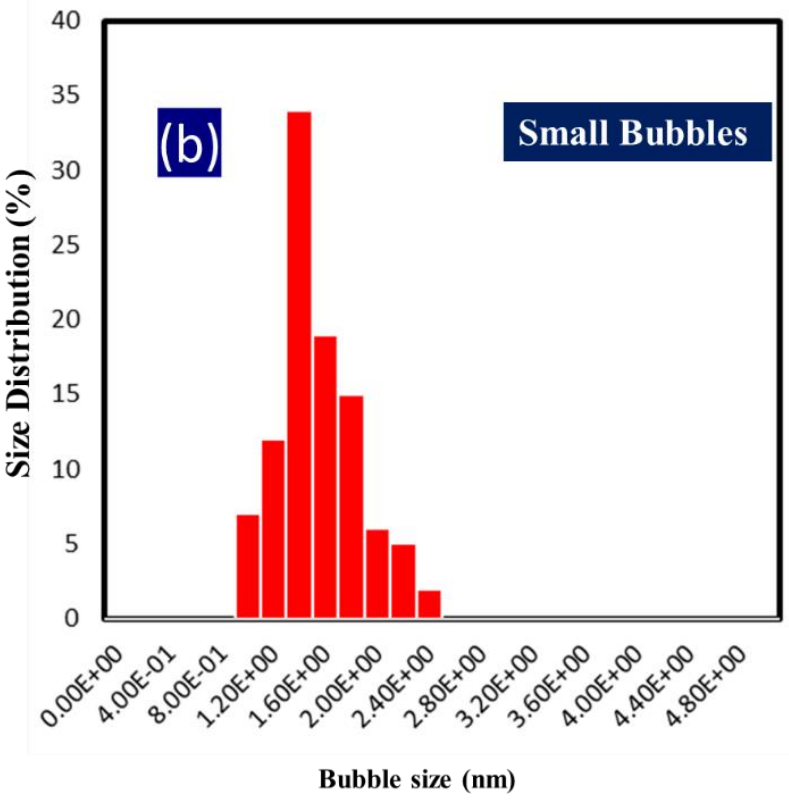

Bubble size (nm)

Figure 13: (a) Bright field image of the Region 1 of the TEM foil. In region 1 only nano bubbles have formed and its corresponding bubble size distribution is presented in (b) monomodal size distribution of Xe bubbles in region 1, with average size of $\sim 1.7 \mathrm{~nm}$

\subsubsection{Bubble Size Distribution and Density in Region 2}

The Xe bubbles formed in this region are of two distinct sizes. There are bubbles whose dimensions vary within $1.4 \mathrm{~nm}$ to $4 \mathrm{~nm}$, and also significantly larger bubbles are identified whose dimensions vary from $15 \mathrm{~nm}$ to $35 \mathrm{~nm}$. More details can be found in Figure 14 (a). The exact bubble size distribution (\%) details can be found in figure 14 (b). The estimated bubble density for this region is $\sim 5.92 \mathrm{e}+17 / \mathrm{cc}$ for the small bubbles and $\sim 8 \mathrm{e}+15 / \mathrm{cc}$ for the larger nano bubbles. Even though 
the individual distribution of bubbles size within their group are monomodal, overall Region 2 has a Bi-modal bubble size distribution.
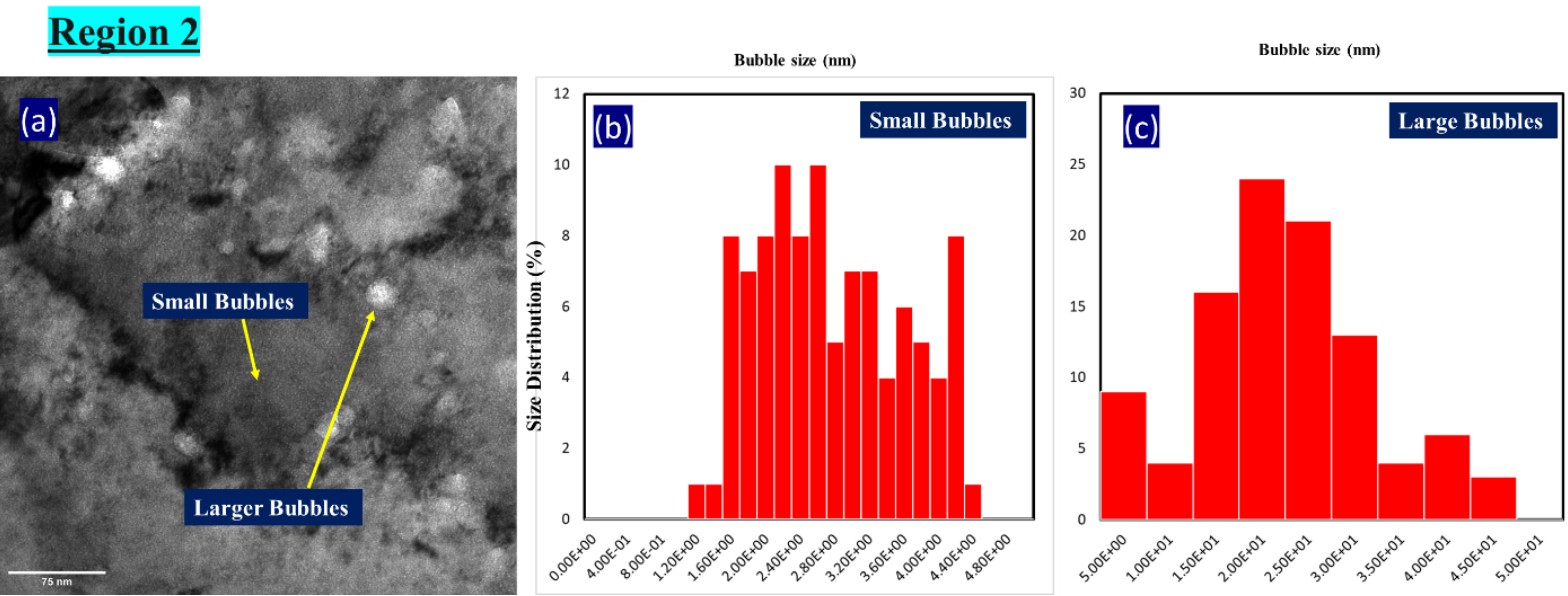

Figure 14: (a) Bright field image of the Region 2 of the TEM foil. In region 2 both small and large nano bubbles have formed and its corresponding bubble size distribution is presented in (b) for only small nano bubbles: a monomodal size distribution of Xe bubbles have been identified, with average size of $\sim 3.0 \mathrm{~nm}$, (c) for only large nano bubbles: a similar monomodal size distribution of Xe bubbles have been identified, with average size of $\sim 22$ nm.

\subsubsection{Bubble Size Distribution and Density in Region 3}

In Region 3 both small and large nano bubbles have formed, including satellite bubbles that are observed around a larger nano bubble as shown in Figure 15 (a). The corresponding bubble size distribution is presented in Figure 15 (b) shows only small nano bubbles: a monomodal size distribution of Xe bubbles have been identified, with average size of $\sim 3.0 \mathrm{~nm}$, and Figure 15 (c) shows only large nano bubbles: a similar monomodal size distribution of Xe bubbles have been identified, with average size of $\sim 52 \mathrm{~nm}$. Figure 15 (d) shows satellite nano bubbles forming around larger nano bubbles with a monomodal distribution of $\sim 4.2 \mathrm{~nm}$ avg. size. The estimated bubble density for this Region 3 is $\sim 9.6 \mathrm{e}+16 /$ cc for the small bubbles, $2 \mathrm{e}+15 / \mathrm{cc}$ for the larger nano bubbles and 3.6e+16/cc for the satellite bubbles. Similar to Region 2, overall, this region has Bimodal bubble size distribution. 


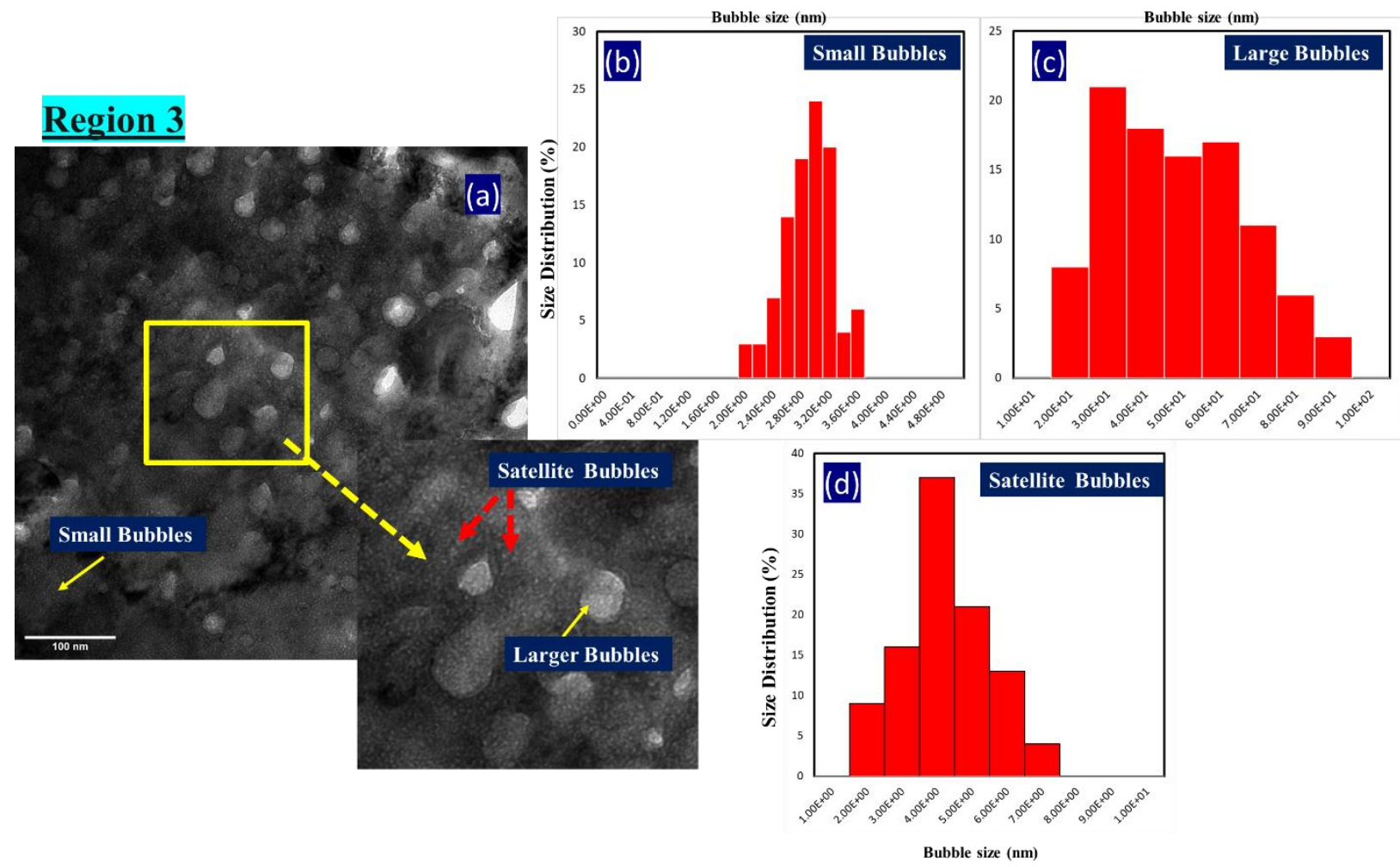

Figure 15: (a) Bright field image of the Region 3 of the TEM foil. In region 3 both small and large nano bubbles have formed, including satellite bubbles can be observed around a larger nano bubble. The corresponding bubble size distribution is presented in (b) for only small nano bubbles: a monomodal size distribution of Xe bubbles have been identified, with an average size of $\sim 3.0 \mathrm{~nm}$, (c) for only large nano bubbles: a similar monomodal size distribution of Xe bubbles have been identified, with average size of $\sim 52 \mathrm{~nm}$ and (d) satellite nano bubbles forming around larger nano bubbles also showed a monomodal distribution, with $\sim 4.2 \mathrm{~nm}$ avg. size.

\subsection{Comparison between Bubble Size Distribution}

In order to perform a one-to-one comparison, the bubbles formed within the grain have been considered for both temperatures. This is done in order to avoid any artificial skewing of the bubble size distribution towards larger dimensions due to presence of grain boundaries. Grain boundaries generally behave as a sink for defects; thus, Xe gas atoms will prefer to diffuse to the grain boundary to lower the free energy of the system. The parameters that have been selected to perform this comparison are: (a) average bubble size and (b) bubble density based on the 3 specific regions selected for both cases. The details are presented in the Table 3. 
Table 3: Comparison between bubble size distribution formed at $450{ }^{\circ} \mathrm{C} \& 750{ }^{\circ} \mathrm{C}$

\begin{tabular}{|c|c|c|c|}
\hline Foil region & Parameters & $\mathbf{4 5 0}^{\circ} \mathbf{C}$ & $\mathbf{7 5 0}^{\circ} \mathbf{C}$ \\
\hline \multirow{3}{*}{ Region 1 } & $\begin{array}{c}\text { Bubble } \\
\text { density }\end{array}$ & $\sim 1.2 \mathrm{E}+18 / \mathrm{cc}$ & $\sim 9.6 \mathrm{e}+17 / \mathrm{cc}$. \\
\cline { 2 - 4 } & $\begin{array}{c}\text { Avg. Bubble } \\
\text { size }\end{array}$ & $\sim 1.4(+/-0.2) \mathrm{nm}$ & $\sim 1.7(+/-0.2) \mathrm{nm}$ \\
\hline \multirow{3}{*}{ Region 2 } & Bubble & $\sim 8.2 \mathrm{e}+17 / \mathrm{cc}$ & $\sim 5.92 \mathrm{e}+17 / \mathrm{cc}$ (small bubbles) \\
& density & & $\sim 8 \mathrm{e}+15 / \mathrm{cc}($ Large bubbles) \\
\cline { 2 - 4 } & Avg. Bubble & $\sim 1.5(+/-0.2) \mathrm{nm}$ & $\sim 3.0(+/-0.2) \mathrm{nm}$ \\
& size & & $\sim 22.0(+/-0.2) \mathrm{nm}$ \\
\hline \multirow{3}{*}{ Region 3 } & Bubble & $\sim 8.2 \mathrm{e}+17 / \mathrm{cc}$ & $\sim 3.6 \mathrm{e}+16 / \mathrm{cc}($ Satellite bubbles) \\
& density & & $\sim 2 \mathrm{e}+15 / \mathrm{cc}($ Large bubbles $)$ \\
\cline { 2 - 4 } & Avg. Bubble & $\sim 3(+/-0.2) \mathrm{nm}$ & $\sim 3.0(+/-0.2) \mathrm{nm}$ \\
& size & & $4.2(+/-0.2) \mathrm{nm}$ \\
& & & $52(+/-0.2) \mathrm{nm}$ \\
\hline
\end{tabular}

From Table 3, it is clear at $750{ }^{\circ} \mathrm{C}$, with same amount of dose $\left(8.94 \mathrm{E}+17\right.$ ions $\left./ \mathrm{cm}^{2}\right)$ received, the $\mathrm{Xe}$ gas bubbles seems to coarsen more easily compared to $450^{\circ} \mathrm{C}$, These is evident from the consistently bigger bubble size distribution for the $750^{\circ} \mathrm{C}$ sample starting from Region 1 through Region 3. 


\section{Future Work}

Elemental characterization studies, such as HAADF and EELS performed in TEM will be beneficial for better understanding the bubble formation and coarsening. This test will verify whether any phase separation/decomposition is occurring at higher temperature. Detailed studies in regard to the dislocation formation and its effect over bubble morphology should be also performed. Additional swift ion irradiation tests at different doses (in steps) at the same temperature would be necessary to further develop understanding regarding the gas bubble formation, evolution and agglomeration.

\section{Conclusions}

In this study, $84 \mathrm{MeV}$ swift $\mathrm{Xe}$ ion irradiation was used to implant $\mathrm{Xe}$ ions in $\mathrm{UC}_{1-\mathrm{x}} \mathrm{N}_{\mathrm{x}}$ fuel kernels at $450^{\circ} \mathrm{C}$ and $750^{\circ} \mathrm{C}$ to simulate fission gas behavior of this fuel during in-pile irradiation. From the post irradiation examination analysis, it can be concluded at $750^{\circ} \mathrm{C}$, with same amount of dose received, the Xe gas bubbles seems to coarsen much more easily compared to $450^{\circ} \mathrm{C}$. This is evident from the consistently bigger bubble size distribution for the $750^{\circ} \mathrm{C}$ sample starting from Region 1 through Region 3. The results generated for fission gas bubble evolution observed in this study can be used to support fuel performance models for $\mathrm{UC}_{1-\mathrm{x}} \mathrm{N}_{\mathrm{x}}$ fuel kernels.

\section{Acknowledgement}

This work was sponsored by the U.S. Department of Energy, Office of Nonproliferation Research and Development in the U.S. National Nuclear Security Administration Office of Defense Nuclear Nonproliferation under Contract DE-AC02-06CH11357. 


\section{References}

[1] A. M. Yacout, in AIP Conference Proceedings, volume 2160, AIP Publishing LLC, p. 050004.

[2] M. Pellin, A. M. Yacout, K. Mo, J. Almer, S. Bhattacharya, W. Mohamed, D. Seidman, B. Ye, D. Yun, R. Xu, et al., Journal of nuclear materials 471 (2016) 266-271.

[3] J. F. Ziegler, M. D. Ziegler, J. P. Biersack, Nuclear Instruments and Methods in Physics Research Section B: Beam Interactions with Materials and Atoms 268 (2010) 1818-1823.

[4] R. E. Stoller, M. B. Toloczko, G. S. Was, A. G. Certain, S. Dwaraknath, F. A. Garner, Nuclear instruments and methods in physics research section B: beam interactions with materials and atoms 310 (2013) 75-80.

[5] B. Beeler, Y. Zhang, M. Okuniewski, C. Deo, Journal of Nuclear Materials 508 (2018) 181194.

[6] G. S. Was, Fundamentals of radiation materials science: metals and alloys, springer, 2016.

[7] Wolfgang Windl, Thomas J Lenosky, Joel D Kress, Arthur F Voter, "First-principles investigation of radiation induced defects in $\mathrm{Si}$ and $\mathrm{SiC}$,", Nuclear Instruments and Methods in Physics Research Section B: Beam Interactions with Materials and Atoms, Volume 141, Issues 14, 1998. 


\section{Argonne $\mathbf{A}$}

\section{Nuclear Science \& Engineering Division}

Argonne National Laboratory

9700 South Cass Avenue, Bldg. 208

Argonne, IL 60439

www.anl.gov 